\title{
Fantasy or Reality: The Historical Development of Video Games in Japan and Western Countries
}

\author{
Shuowei $\mathrm{Wu}^{1, \mathrm{a}}$ \\ ${ }^{1}$ International Department, Fuyang High School, Hangzhou 310000, P.R. China \\ a945524259@qq.com
}

Keywords: Video Games, fantasy, reality, hero setting, game types

\begin{abstract}
Video games are big business in both western and Asian countries. Japanese video games are representatives of those in Asia. Although there are a lot of differences between western and Japanese video games, they have become important feature in the economies. In this article, the author talks the main features and differences in Japanese and western video games. Besides, the author also discusses the future trends of Japanese video games which have already become a main competitor in the global video game market.
\end{abstract}

\section{Introduction}

Video games are big business. Globally, the industry earns around $\$ 18.4$ billion in revenue and continues to grow. Video games, therefore, are an important feature in the economy. They utilize the latest trends in technology and in the creative arts [1]. They also reflect changing sensibilities and how people choose to entertain themselves in today's globalized world. Yet what lessons can be derived from analyzing the development of the video game industry? In comparing prominent games from the western countries, on the one hand, and Japan, on the other, key differences emerge in the main story lines then spread to the other parts of the games like the depictions of the hero and, the visual and game types. Japanese games are prone to feature fantasy stories which are imaginative and idealized while Western games emphasize the importance of reality and choice in the main stories. Whereas the action in Japanese games tend to be constant, Western games are constantly evolving to cater to the changing and fickle ideals of their market, most recently heavily influenced by political correctness. This paper will argue that the differences between Japanese and western video games are most visibly represented in their different approaches to fantasy and reality and demonstrate how this disparity is because of the primary influence of political correctness in western societies.

\section{The plot: fantasy or reality}

Every video game has many different components. The most significant features are the plot or the games' main story. The plot, which is the values that the game developers want to tell the game player, can influence other building blocks of the video games. The nature of the main story reflects societal and cultural values. There are big differences in narrative and plot lines in Japanese and western games. In Japan, the main story is usually about a teenager who acquires some form of superpower and needs to find companions to save the world from the demon's hand. This character is evident in many classical Japanese games, like Final Fantasy, Dragon Quest and the series of Tales. Although recently many companies want to change their game's story, like to make hero a villain and want to destroy justice such as Tales of Berseria, the plot still remains essentially the same. In playing out his or her battles, the hero usually needs to collect more power and become stronger to be able to finally defeat the demons with his or her friends. At that point, the world will become peaceful. Order has been restored and the story goes back to square one. However, the stories of western games are generally much more complicated. For example, it is elusive to define a hero in western games merely as a hero or villain. They are not subject to simple binaries. He or she can have a lot of advantages, but as the same time, they display a lot of vulnerability. Reality is 
always an important element in western games. Additionally, Western video games' main stories also emphasize an element of choice. The game can be dynamic and unpredictable because the trajectory can change depending on what choices the players make. For example, in the Witcher 3's main story, the company created a task for the player to help an old woman who is the leader of the orphanage. She allows the player to kill a devil in order to protect the children. However, when the player meets that devil, they discover that there are actually 3 witches who will eat the children in the orphanage and the old woman knows nothing about it. Consequently, the player is given two choices: one is to kill the devil to accomplish the task but then the children will be killed and eaten by the 3 witches. The second alternative is to help to release that devil. Then the devil will save the children but the old women will die because 3 witches will be angry at her since she outlasted the children. A lot of people release the devil because they think that many children's life is more important than the life of one old woman. However, if the player chooses to release the devil, it will kill an entire village. Unlike, Japanese games with their singular endings, western games have many possible outcomes. A player's decision can significantly impact the final scenario. It is not always clear whether the hero will actually prevail whereas in Japan the hero will always win and get what he or she wants. Western video games may not want to resort to such simple binaries of good and evil due to changes in cultural expectations influenced by political correctness [2].

\section{Political correctness in western societies}

Nowadays, political correctness is influencing a lot of the culture industry. It seems like the general population has become hyper-sensitive. Therefore, video game developers have to be very careful in presenting plots and heroes that conform to the ethos of political correctness. For example, human rights are an important element of western games. In the game Frostpunk, a player needs to be a leader of a city after there is a big war in the world and the earth resorted back to Ice Age. In this game, players need to regulate citizens' daily life like how much times people work in a day. If a player lets people work more than 8 hours, the workers will be unsatisfied and may even have a rebellion. However, such a movement cannot make any sense in lots of eastern countries like China. According to the comments under the steam, which is the biggest video games market online, this game is doing very well in almost every aspect from a Chinese perspective. However, they cannot understand that since the world is coming to the end and people may all die that these workers would actually care about how many hours they need to work for a day? In fact, political correctness is a big problem in western society.

By contrast, Japanese games do not always have this kind of setting. In the traditional Japanese RPG games, the game manufacturers usually pay more attention to the depiction of the character. In eastern society, political correctness has not yet been a big problem to the culture industry. Game designers can still design a pretty girl as a Pay-to-play character and no one who is influential will say anything about it. However, in western society, it will be a really embarrassing situation because of women's rights and could lead to boycotts of the product and plummeting sales. Hypothetically, if the company behind one of the most popular video games globally, League of Legends, develops a new female hero who is very pretty and sexy, feminists will protest it because the game is objectifying women. Yet if the company depicts a new female hero as strong but not have a very good-looking face, feminists will protest because the game is vilifying women. Further, if the game company does not make a new women hero for a long time and only develops male heroes, feminists will also protest because the game is implying that women do not have the same status as man. As the result, nowadays in western video games, company are usually very careful in both the setting of the characters and the main story to avoid being ostracized by political correctness [3].

\section{Difference of hero setting}

In the culture industry, the hero is an important part of the productions, the setting of hero can reflect the ideal figure of human in the society. Certainly, there are a lot of differences between Japan and western community. In Japan, game akers prefer to set their heroes as teenagers or young 
adults with a superpower. Typically, their task is to gather friends to save the world from the demon. For example, the hero of Final Fantasy XV, Noctis is a case in point. He is the prince of a country and is only 20 years old when he started his journey to revenge and rebuild his country. Also, the best Japanese Role-Playing Game (JRPG) in 2017, Persona 5, the hero is a high school student who has the ability to dive into others' spirit world and steal their distorted desire to let bad people realize they are wrong so that they surrender to the police. However, by contrast, western video games are always preferring to set their hero as a strong, wise, middle-aged man. Geralt, who is the hero of the Witcher 3, is a typical example. He is the Witcher who hunts the monster to earns money for several centuries. One of the most popular video games, Grand Theft Auto (GTA5), there are 3 heroes who are all adults, one is a black, one is a middle age man who are used to be criminal, and the last one is still a criminal who is irritable. These three men are all suffering from the large pressure which experienced by lot of people in real society.

The setting of the heroes can sometimes reflect some social problems in a country. For example, in the recent years, Japan has experienced Sub-replacement fertility. The abnormal population pyramid brings a lot of problems to Japan's social structure. The relatively large portion of elderly citizens puts a lot stress on the young workers. This fact may be a leading cause to why Japan is the one of the countries who has the highest suicide rates in the world. As the result, the images of teenagers are very like the hope of the future in Japan [4].

Geralt, hero of the Witcher 3

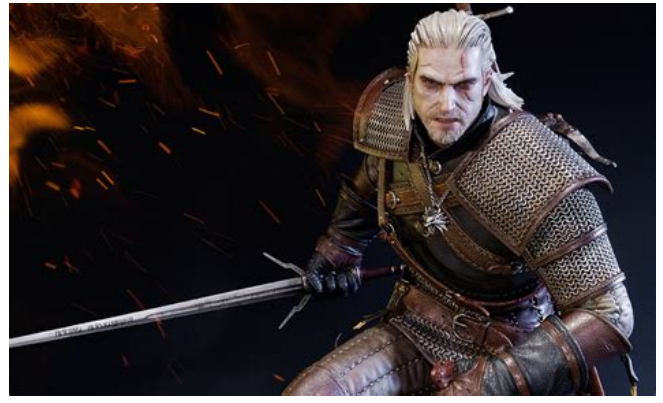

Three heroes of Grand Theft Auto

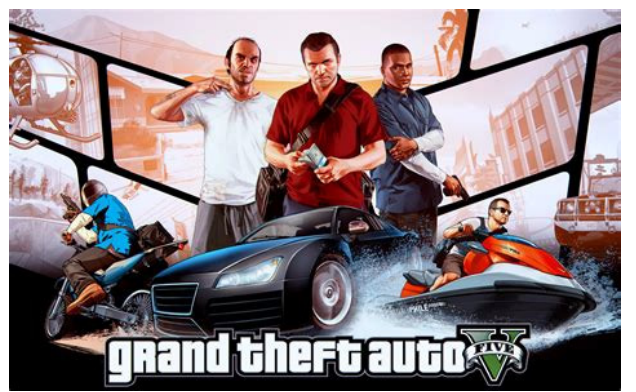

\section{Differences of game types}

The way hero fight with the villain in a game is also an important reason when player praise or criticize a game. The types of video games, especially RPG games of Japanese and western games are also different. For the traditional Japanese RPG games, often called JRPG (Japanese Role-Playing Game), have all of the characteristics of Japanese game we have analyzed before. However, in this part, we will mainly discuss the differences of the way the hero fights in Japanese and Western games. In most of the JRPG, the action is turn-based, which means that hero's team and villain attack or defend by turns. During the hero's turn, the player has one or more chance to let the hero attack, cast a magic, defend or use the medicine to heal themselves. Then comes the villain's turn which controlled by AI. The villain always has the same chance to attack, cast a magic spell or defend. In the hero's turn, the villain can do nothing but wait to be attacked. Whoever can empty others' HP (Health Point) first, can win in this form of fighting. However, western RPG games have more built-in unpredictability. While fighting, the villain can while the player is manipulating the hero to fight or shoot. The player needs to let the hero attack they villain when they are also being attacked. In this kind of manipulating ways, players always need to act immediately when the villain does something. In JRPG, players are supposed to calculate more: However, in western games, it depends on a player's velocity of reaction. The distinctions of the game types can also be explained by the differences of the main story. Since JRPG prefer to make the story like a line, some strong villains will emerge earlier in the story. This early appearance, emphasizes the power of the villains. The games will arrange a fight between heroes and villains and hero will lose. Since players cannot react in villains' turn in turn-based fight, it is common to design the fight that heroes can only hurt villain a little by their strongest skill but villains can defeat the hero by just one skill which players called it "defeated by the story" that are less in the western 
video games.

Different Visual Styles

\begin{tabular}{|l|l|l|l|}
\hline & Types & $\begin{array}{l}\text { Can Hero React } \\
\text { Immediately }\end{array}$ & Depend On \\
\hline JRPG & Turn-based & No & Predicting and Calculating \\
\hline $\begin{array}{l}\text { Western Video } \\
\text { Games }\end{array}$ & Action Games & Yes & Reaction ability and actions per minutes \\
\hline
\end{tabular}
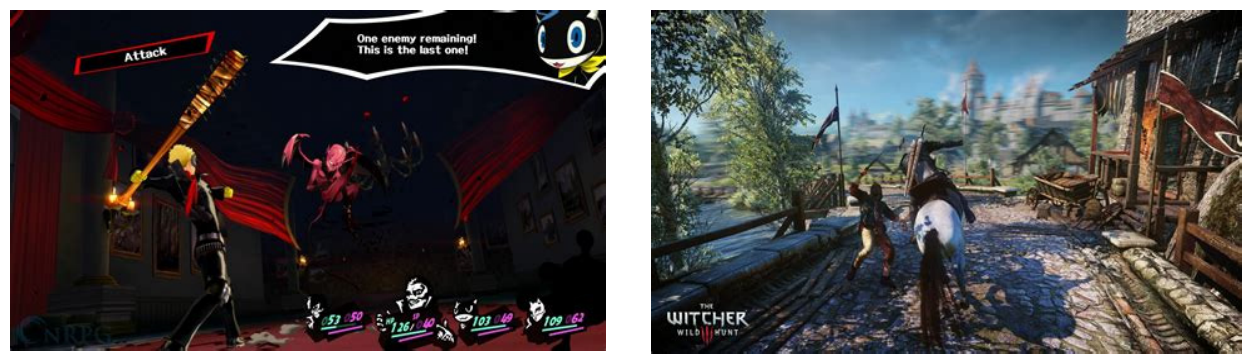

When a player starts a new game, the first thing they notice and use to evaluate the game is the image, or the visual type of the game. One of the biggest and most obvious difference between Japanese game and Western is how they are visually presented. While a lot of western players criticize that Japanese games are always too vibrant and cartoonish. Japanese players, in turn, consider western games' as too realistic and dark [5]. Under this paragraph, the left image is from a typical Japanese game called Tales of Berseria and the right one is a typical western game. We can easily see that compared to the western games, Japanese games are brighter. Japanese developer Keiji Inafune explained that since Japanese grow up with cartoon and manga, which features more abstract and stylized drawings, Japanese video games tend to follow that general aesthetic style. At the same time, western players are used to realistic movies and TV show. As the result, they will choose to develop and play the video games which are more realistic Japanese games' main stories are usually brighter and smoothly so the visual types of Japanese games are usually more colorful. In contrast, western games usually have a darker story than the Japanese games. The hero always needs to give up something in order to get something. As a result, western games' visual types are always darker than the Japanese games.

Japanese Game "Tales of Berseria"

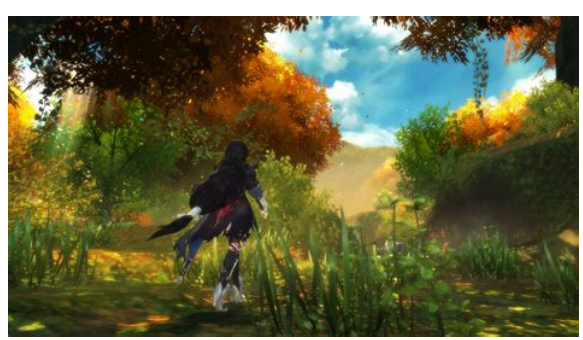

Western Game

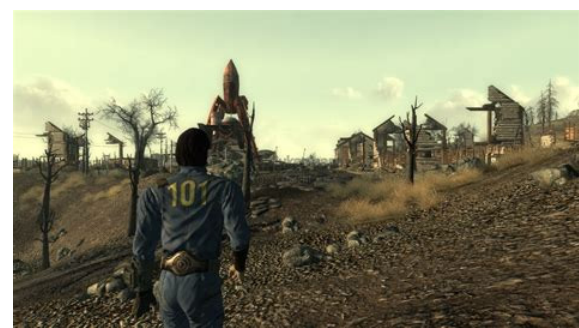

\section{Conclusion}

Video games are no longer just a form of amusement for people to entertain themselves. Neither is it "Electronic Heroin" as described by many people. However, video games are an art form which can reflect cultural values and personal feelings; video games are the movies which audiences can participate in the story; video games are the worlds which are developed by both the developer and player. Recently, with the develop of the Internet, Japanese games have started to enter the global market. In order to boost their sales an increasing number of Japanese companies are making the games which are starting to resemble typical western games. For example, Final Fantasy XV uses a typical western battle mode. Further, the series of Dark Souls is almost totally a western game but developed by the Japanese. These trends indicate that, in the future, the video games of western and 
Japanese will increasingly resemble each. It is difficult to ascertain whether this is a positive or negative development. What is most, important, however, is that video games remain mysterious, exciting, and beautiful, and continue to provide players with the entertainment that they seek.

\section{Reference}

[1] ESA, Annual report 2017, Entertainment Software Association, 2017.

[2] Z.X. Zhou, A research on the difference of game character designing in artistic expression between China and western countries, Journal of Nanjing Arts Institute(Art and Design), vol. 05, pp. 196-198, 2013.

[3] X.M. Wu, Cultural identity and design in globalization - case study by Japanese computer game and animation design, Art Science and Technology, vol. 07, pp. 386-387, 2013.

[4] W.Y. Deng, Japanese cartoon character design based on alienation theory-an interpretation of the alienation of the protagonist in Saint Seiya, Art Panorama, vol. 03, pp. 102-103, 2014.

[5] B. Zhao. Design of personas in video games. Kunming University of Science and Technology, 2010. 